\title{
Structures of intransitive competition network affect functional attributes of plant community under nitrogen enrichment
}

\author{
Qingqing Sun ${ }^{1}$, Junjie Yang ${ }^{2}$, Fengyan Yang ${ }^{1}$, Yuying Zhao ${ }^{1}$, Cunzheng Wei $^{2}$, Guangming \\ Zhang ${ }^{3}$, Xingguo $\mathrm{Han}^{4}$, and Jinshan $\mathrm{Li}^{1}$ \\ ${ }^{1}$ Beijing Forestry University \\ ${ }^{2}$ Institute of Botany Chinese Academy of Sciences \\ ${ }^{3}$ Changzhi Medical College \\ ${ }^{4}$ Institute of Botany, Chinese Academy of Sciences
}

December 10, 2021

\begin{abstract}
Atmospheric nitrogen $(\mathrm{N})$ deposition is a potential danger factor for grassland ecology, and will cause unpredictable consequences to plant communities. However, how plant species interactions response to $\mathrm{N}$ enrichment and then affect ecological functions are not fully known. We investigated how intransitive competition network was related to the functional attributes of plant community under a 13-years N-deposition experiment. Results showed that intransitive competition network was not a single structure, but a complexly interwoven structure of various simple structures. Nested work was more common, accounting for $76.96 \%$, and gained new species at a higher colonization rate than short network did. The network had a long-term mechanism to maintain the small-scale Alpha diversity, and a significant lag effect on the large-scale Gamma diversity. Under the conditions of $\mathrm{N}$ [?] $2 \mathrm{~g} \mathrm{~N} \cdot \mathrm{m}-2 \cdot$ year-1, without mowing and under high fertilization frequency, the increase of network complexity significantly decreased plot biomass gradually. The relationship between biomass and network complexity is quadratic curves, also between abundancy and the complexity, but with the opposite bending directions, which indicated that biomass and abundance were complementary to each other, which may be a mechanism of maintaining the relative balance of species competition. In addition, the decrease of species asynchronism changing with the increase of N-enrichment gradually destroyed ecosystem stability. However, at medium $\mathrm{N}$ enrichment, intransitive network counteracted the negative effects of $\mathrm{N}$ enrichment and maintained or even improved the biomass ecosystem stability. Our results suggested that intransitive competition network is an internal mechanism of self-restoration of a grassland ecosystem. Under nitrogen enrichment conditions, competitive networks complexity is reduced, leading to a reduction in species diversity. These analyses emphasize the important role of intransitive network structure to stabilize grassland ecosystem. In order to achieve sustainable development of grassland, it is indispensable to control nitrogen addition rate.
\end{abstract}

Title page

Title :Structures of intransitive competition network affect functional attributes of plant community under nitrogen enrichment

Sun Qingqing, ${ }^{\mathrm{a}, 1}$, Yang Junjie ${ }^{\mathrm{b}, 1}$, Yang Fengyan ${ }^{\mathrm{a}}$, Zhao Yuying ${ }^{\mathrm{a}}$, Zhang Guangming ${ }^{\mathrm{c}}$, Wei Cunzheng ${ }^{\mathrm{b}}$, Han Xingguo ${ }^{\mathrm{b},{ }^{*}}$, Li Jinshan ${ }^{\mathrm{a}, 1, *}$

${ }^{\text {a }}$ College of Science, Beijing Forestry University, Beijing 100083, China

b State Key Laboratory of Vegetation and Environmental Change, Institute of Botany, Chinese Academy of Sciences, Beijing 100093, China

${ }^{c}$ Department of Pharmaceutical Science, Changzhi Medical College, Changzhi 046000, China 
* Corresponding author : Han Xingguo, e-mail:xghan@ibcas.ac.cn; Li Jinshan, email:lijinshan@bjfu.edu.cn

Acknowledgements: This work was supported by the National Key Research and Development Project of China (2016YFC0500705) and the Fundamental Research Funds for the Central Universities (2015ZCQ-LY01).

Conflict of interest : The authors declare they have no competing interests.

Authors contributions:Sun Q.Q. and Li J.S. conceived the ideas and designed methodology; Yang J.J. collected the data; Sun Q.Q., Yang J.J. and Li J. S. analyzed the data and wrote the manuscript with feedback from Zhang G.M., Yang F. Y. and Zhao Y. Y. All authors contributed critically to the drafts and gave final approval for publication.

\begin{abstract}
Atmospheric nitrogen $(\mathrm{N})$ deposition is a potential danger factor for grassland ecology, and will cause unpredictable consequences to plant communities. However, how plant species interactions response to $\mathrm{N}$ enrichment and then affect ecological functions are not fully known. We investigated how intransitive competition network was related to the functional attributes of plant community under a 13-years N-deposition experiment. Results showed that intransitive competition network was not a single structure, but a complexly interwoven structure of various simple structures. Nested work was more common, accounting for $76.96 \%$, and gained new species at a higher colonization rate than short network did. The network had a long-term mechanism to maintain the small-scale Alpha diversity, and a significant lag effect on the large-scale Gamma diversity. Under the conditions of $\mathrm{N}$ [?] $2 \mathrm{~g} \mathrm{~N} \cdot \mathrm{m}^{-2} \cdot \mathrm{year}^{-1}$, without mowing and under high fertilization frequency, the increase of network complexity significantly decreased plot biomass gradually. The relationship between biomass and network complexity is quadratic curves, also between abundancy and the complexity, but with the opposite bending directions, which indicated that biomass and abundance were complementary to each other, which may be a mechanism of maintaining the relative balance of species competition. In addition, the decrease of species asynchronism changing with the increase of $\mathrm{N}$-enrichment gradually destroyed ecosystem stability. However, at medium $\mathrm{N}$ enrichment, intransitive network counteracted the negative effects of $\mathrm{N}$ enrichment and maintained or even improved the biomass ecosystem stability. Our results suggested that intransitive competition network is an internal mechanism of self-restoration of a grassland ecosystem. Under nitrogen enrichment conditions, competitive networks complexity is reduced, leading to a reduction in species diversity. These analyses emphasize the important role of intransitive network structure to stabilize grassland ecosystem. In order to achieve sustainable development of grassland, it is indispensable to control nitrogen addition rate.
\end{abstract}

Key words: biodiversity, complexity, ecosystem stability, nested network, species asynchrony

\title{
1. Introduction
}

Nitrogen (N) fertilization management on natural grasslands and pastures can significantly increase yield of plants and animals, which has brought great convenience and abundant benefits to modern agriculture and animal husbandry (Tilman 1987; Zhang et al. 2015). Nutrient enrichment generally increases primary production but reduces biodiversity. Theoretically, nutrient enrichment can destabilize ecosystems (Rosenzweig 1971). In grassland ecosystem, the species extinction and community composition are caused by overfertilization or atmospheric Nitrogen deposition (Clark and Tilman 2008; Socher et al. 2013; Zhang et al. 2019).

Some studies (Freckleton and Watkinson 2001; Wang et al. 2020)) clearly indicate that changes in competitive intensity are also key drivers of community composition. The intensity is a kind of quantification of competition structure, while competitive structure changes with the variation of environment (Allesina and Levine 2011) and is susceptible to the influence of human factors (Soliveres et al. 2015). Competition network is an important determinant for community functions, with a gradient from weak competition community to strong competition community (Maynard et al. 2017b). Structure of networks is a driver of biodiversity and 
coexistence in natural communities (Sun et al. 2021). In addition, the nature and intensity of competitive interactions also affect growth, productivity, and biomass of surviving individuals. Therefore, structure of competition networks, i.e., the result of pairwise species competition (Allesina and Levine 2011), should play an important role in community attributes.

The immediate cause of existence for competition is that the species composition in the focus community, since species have different functional and life-history characteristics, the particular combination of which maintains intransitivity or hierarchical competition (Aschehoug et al. 2016). Intransitive competition is more common in vascular plants, and there is a significant positive relationship between species richness and intransitivity (Soliveres et al. 2015; Gallien 2017a), which reveals complex competitive interactions among species (Allesina and Levine 2011; Engel and Wetzin 2008) and greatly promotes the theory of species symbiosise. Empirical analysis and simulation study (Ulrich et al. 2017) both showed that intransitive competition, as mechanism for maintaining high alpha diversity (Laird and Schamp 2006), can promote symbiosis of competitors. Therefore, understanding the good competition is important to understand the way that community is structured and how coexistence of species occurs.

In addition, ecosystems are always exposed to environmental perturbations that tend to alter temporal stability of plant communities (Ma et al. 2017; Douda et al. 2018). Species asynchrony occurs in natural communities due to interspecific competition and environmental stresses. Empirical observations have shown that there are positive covariances among species biomass in many communities, which do not indicate absence of competitive interactions. Besides the effects of diversity itself on community function, the interaction of diversity and competition, as two key attributes, determines biomass production, respiration, and carbon-use efficiency. On other hand, availability of abiotic resources varying over time, potentially breaks down inherent species competition. However, it is unclear to understand how species competitive interactions respond to $\mathrm{N}$ enrichment and affect plant community function (Gross et al. 2017; Mouillot et al. 2011).

We tested the following hypotheses: (1) the intransitive network with nested structures is more common in vascular plants; (2) at the small scale, the function of nested network to maintain species richness was more significant; (3) the intransitive network complexity could maintain the relative balance between biomass and plant number; (4) the negative effect of nitrogen can be mitigated by intransitive network.

\section{Materials and methods}

\subsection{Experimental sites and sampling}

The field experiments were carried out on the temperate steppe $\left(43^{\circ} 32{ }^{\prime} 51\right.$ "N, $\left.116^{\circ} 40^{\prime} 23^{\prime \prime} \mathrm{E}\right)$ in Xilinhot, Inner Mongolia Autonomous Region, China, where belongs to the typical temperate semi-arid climate and has relatively flat terrain. Since 1999, 50 hectares of the experimental area had been fenced off to eliminate the impact of large-scale grazing, and no fertilizer had been applied before the beginning of the experiment. The mean annual temperature in $2008-2020$ was $1.45^{\circ} \mathrm{C}$, the mean temperature in the growing season was $17.04^{\circ} \mathrm{C}$, the annual precipitation was $329.9 \mathrm{~mm}$, and the precipitation in the growing season was $227.6 \mathrm{~mm}$. Two C3 perennial herbaceous plants, Stipa grandis and Leymus chinensis, are the dominant species in the vegetation community.

The nitrogen used in the experiment was ammonium nitrate $\left(\mathrm{NH}_{4} \mathrm{NO}_{3},>99 \%\right)$, which was added to the experimental plots during the growing season and the non-growing season by wet deposition (ammonium nitrate dissolved in distilled water) and dry deposition (ammonium nitrate mixed in fine sand), respectively. Species traits such as biomass, plant abundance et, al., as the sample data, were measured on a $0.5 \mathrm{mx} 2 \mathrm{~m}$ strip plot in every experimental block of $8 ?^{2}$. The experiments designing with completely randomized block, and setting up with 9 nitrogen annual adding rates $\left(0,1,2,3,5,10,15,20,50 \mathrm{~g} \mathrm{~N}^{*}\right.$ ?-2*????-1 $\left.^{-1}\right), 2$ kinds of fertilization frequency ( 2 times a year, 1 time a month), and 2 processings of mowing (yes or not), in addition to two control groups, a total of 38 different treatments were performed, each of which was repeated 10 times. 


\subsection{Methods}

\subsubsection{Species richness}

Based on theoretical work (Wang and Loreau 2014), as well as previous empirical studies (e.g., Wilcox et al. 2017; Zhang et al. 2019), the Alpha diversity was defined as the species richness of $1 \mathrm{~m}^{2}$ plot (small scale), and the Gamma-diversity as the total richness of 10 repeated plots of $1 \mathrm{~m}^{2}$ (large scale) under a same treatment. In addition, soil ammonium toxicity is greater under $\mathrm{N}$ enrichment, leading to low colonization rate and even high species extinction rate (Zhang 2015). In order to explore the effect of intransitive competition network on the community attributes, species gained or lost have also become the key point of the discussion.

\subsubsection{Spatial variability}

Lloyd's central theory (1967) demonstrated that average density is difficult to explain ecological causality between competition and density regulation. At individual level, Lloyd designed average clumping as a measurement of spatial patches to capture spatial aggregation associated with intraspecific competition for resources. In order to explore the influence of $\mathrm{N}$ enrichments on spatial differences in species richness, we used Lloyd's variance-to-mean ratio, $I=\frac{\sigma^{2}}{\mu^{2}}-\frac{1}{\mu+1}$. Where ? and ? ${ }^{2}$ are the mean and variance of species richness under different treatments or variables. When $\mathrm{I}<1$, the spatial difference of species richness was small and the distribution was more uniform; when $\mathrm{I}>1$, the spatial difference of species richness was great; and when $\mathrm{I}=1$, it is the expectation of the Poisson's random distribution.

\subsubsection{Measurement of intransitivity}

Nitrogen enrichment can reduce environmental heterogeneity in small communities (Western 2001; Fraterrigo et al. 2005), therefore, similar environment is likely to promote similar community dynamics (Wesche et al. 2012). We introduced the Apriori algorithm to mine the species dominant assembly in spatial clumping and ensured that the inference of a species competition network was based on at least 5 plots in 10-repeated ones (Wang et al. 2020; Sun et al. 2021).

Starting from the dominant assembly, the 'reverse engineering' and colonial competition model proposed by Ulrich et al. (2014) was used to simulate the best competition matrix, entries of which are competition coefficients between species. Simulations were done to produce a large number of competitive matrix $C$, as well as transfer probability matrix $P$, obtained from $C$ by colonial competition model. Then Spearman tests between $P U$ and the relative abundance vector $U$ of experimental plots under same treatment were done. The average of Spearman coefficients (??) from the tests was used as a selection index for best $C$ and $P$. Spearman coefficients acquired from the experimental data were generally low, showing that the role of interspecific competition mechanism was relatively small, while environmental heterogeneity (Dufour et al. 2006) or other more important mechanisms (Ulrich et al. 2018) maybe play important role. Therefore, only when $r_{s} \geq 0.6$, interspecific competition is the dominant factor for a assembly, and then the matrix $\mathrm{C}$ was going to be the optimal competition matrix. Species-competition network was built up by the matrix C, in which species were vertices and edge weights were the entries of C.

We used deformation of the Flow Hierarchy (Luo 2011; Sun et al. 2021) to measure the complexity of intransitive network.

$$
\text { Complexity }=\left\{\begin{array}{c}
0, \quad \text { if } \frac{h * c}{N_{\text {node }}}>1 \\
1-\frac{h * c}{N_{\text {node }}}, \text { if } 0 \leq \frac{h * c}{N_{\text {node }}}<1
\end{array}\right.
$$

where $h$ is the measure of flow hierarchy, $N_{\text {node }}$ is the species number of the focal network, and $c$ is a constant. When complexity is 0 , there is only chain structure (e.g., $\mathrm{A}>\mathrm{B}>\mathrm{C}$ ). When complexity is 1 , there are a large loop structures that all member of network in it. 


\subsubsection{Biomass stability and species asynchrony}

Following previous work (Tilman 1999), biomass stability was calculated as $S_{\text {community }}=\frac{\mu_{T}}{\sigma_{T}}$, where $\mu_{T}$ and $\sigma_{T}$ are the interannual mean and standard deviation of community biomass over the 13 years respectively.

For each $1-\mathrm{m}^{2}$ strip, the degree of asynchrony in the population dynamics of constituent species of its local community was quantified as $1-\frac{\sigma_{T}^{2}}{\left(\sum_{i=1}^{M} \sigma_{i}\right)^{2}}$, where $\sigma_{T}^{2}$ is the temporal variance of community biomass, and $\sigma_{i}$ is the standard deviation of biomass of species i in the $M$-species community (Loreau and de Mazancourt 2008).

\subsubsection{Statistical analysis}

Linear or quadratic polynomial least squares regression was used to study the relationships between variables, such as plot biomass and N-addition rates, plant abundance of plot and network complexity etc. The independent sample T-test was used to test the significance of differences among diversity of different kinds of network. The Python packages used in this paper were "StatsModels", "NextWorkX" and "SciPy".

\section{Results}

\subsection{Network structure affects richness}

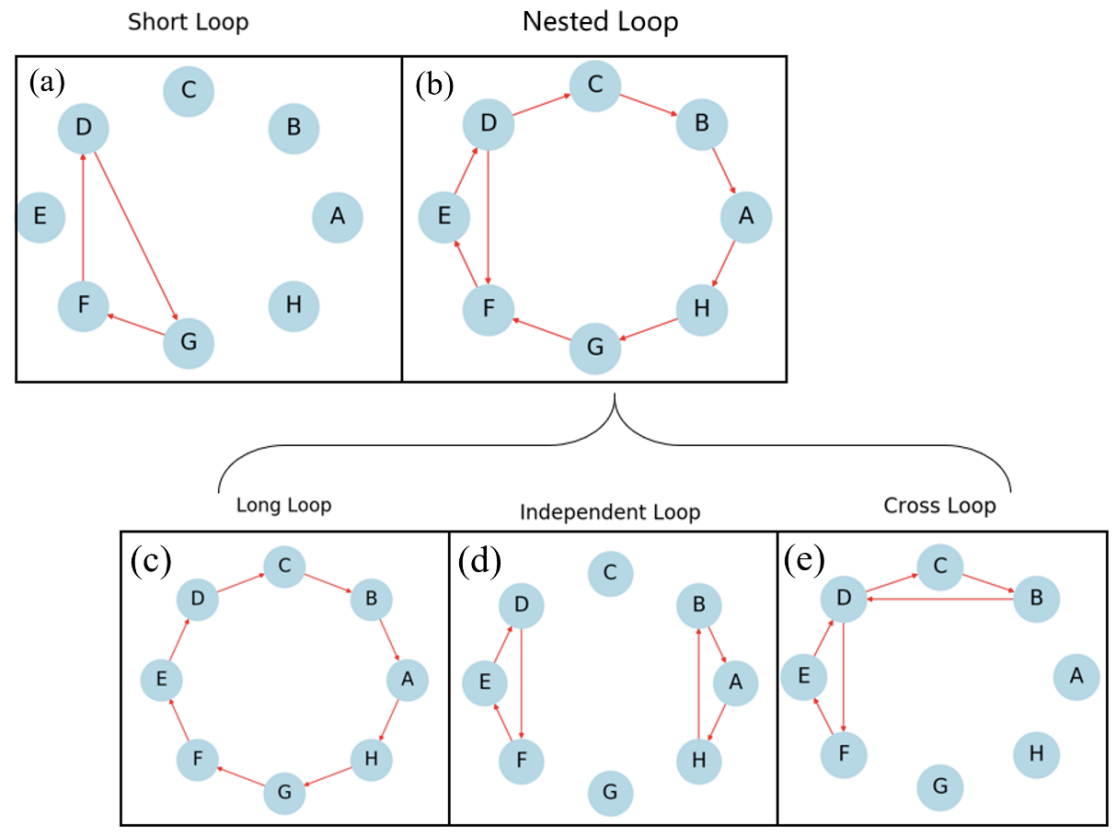

Figure 1The structure of intransitive networks could be divided into five simple forms: short loop (a), nested loop (b), long loop(c), independent loop(d) and cross loop(e). The big brace means that the networks have nested loop always along with structure of long loop, independent loop or cross loop. Nodes in network represent species (letters), and red arrows point to less competitive species.

The structure of the intransitive network was divided into five simple forms: short loop (only one loop of three species, in Fig. 1a), nested loop (a large loop embedded with a small loop in Fig. 1b), long loop (all species fall into the loop, in Fig. 1c), independent loop (there are at least two loops, and no species shared in them, in Fig. 1d), and cross loop (at least two loops with shared and unshared species, in Fig. 1e). In the real plant community, the competitive relationship among species was very complex, and its 
competitive structure was often not a single structure. In the sample plots investigated, there were six kinds of loop-structure combinations of the five simples (in Tab.1), among which the short network, accounting for $23.04 \%$, while the nested network, accounting for $76.96 \%$, in 191 intransitive networks. The short network and the nested network are mutually exclusive, representing relatively simple network and more complex one, respectively.

Table 1 The kinds of combination of the simple loop structures are distributed. The short network, accounting for $23.04 \%$, only contains short loop. The nested network, accounting for $76.96 \%$, contains combination of other simple structures in addition to nested network, and there were five kinds of such combinations.

\begin{tabular}{|c|c|c|}
\hline Structural combination & Frequency & Percentage $(\%)$ \\
\hline Nested Loop 、 Cross Loop & 100 & $76.96 \%$ (Nested network) \\
\hline Nested Loop 、 Long & 18 & \\
\hline $\begin{array}{l}\text { loop - Independent loop } \\
\text { Cross Loop }\end{array}$ & & \\
\hline $\begin{array}{l}\text { Nested Loop 、 Independent loop } \\
\text { Cross Loop }\end{array}$ & 15 & \\
\hline $\begin{array}{l}\text { Nested Loop 、 Long } \\
\text { loop、Cross Loop }\end{array}$ & 13 & \\
\hline Nested Loop 、 Independent loop & 1 & \\
\hline Short loop & 44 & $23.04 \%$ (Short network) \\
\hline
\end{tabular}

(a)
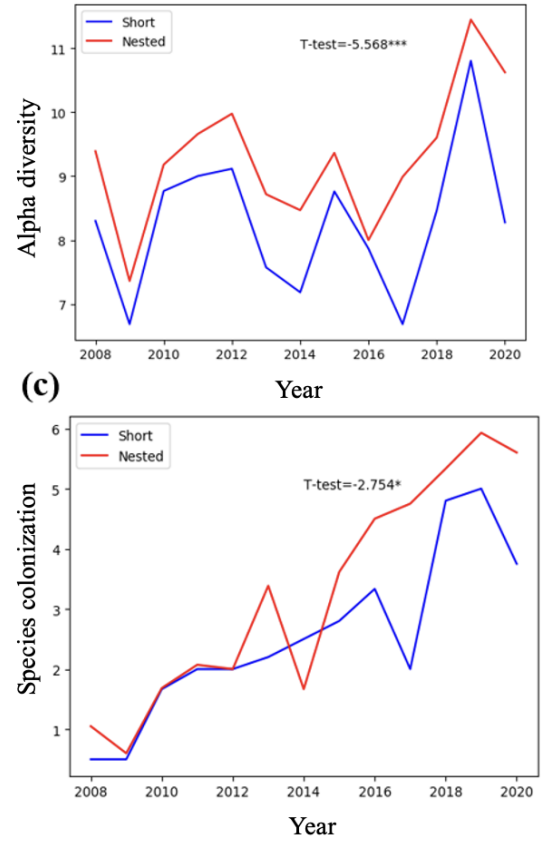

(b)

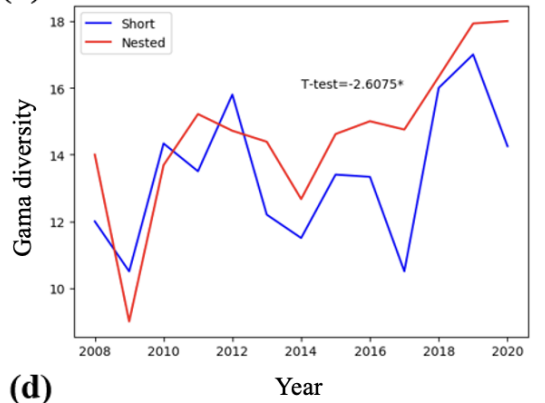

(d)

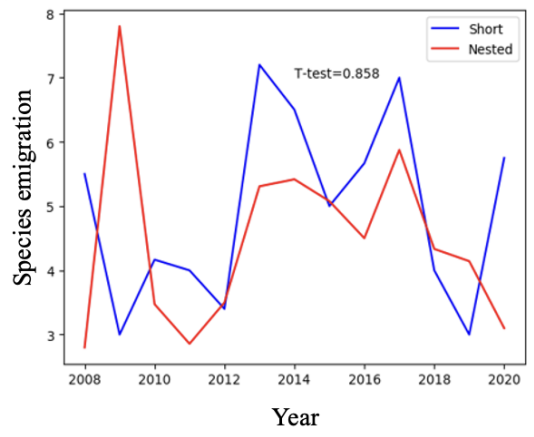

Figure 2 The figure depicts temporal effects of network structure on species diversity of communities. The trends about the effects of the short network (blue line) and the nested network (red line) on the alpha diversity (a), the gamma diversity (b), species colonization (c) and species emigration (d) are given. The independent sample T-test is used to test whether there are significant differences in the effects of the two structures on the community attributes over years. Note: ${ }^{*}<0.05,{ }^{* *}<0.01,{ }^{* * *}<0.001$. 
The effects of short network and nested network on community species diversity were significantly different in various scales. In terms of the small-scale alpha diversity, although affected by abiotic factors, the effects of the two kinds of networks basically showed an increasing trend. Species richness in the nested network is always significantly higher than that in the short network (in Fig. 2a). The nested network was significantly more conducive to maintain of the alpha diversity $\left(T_{\text {test }}=-5.568, P<0.001\right)$. For the large-scale gamma diversity, the community diversity increased significantly over time under the regulation of nested network $\left(T_{\text {test }}=2.6075, \quad P<0.005\right.$, in Fig. $\left.2 \mathrm{~b}\right)$. Nested network is more conducive to the colonization of new species at the later stage of the experiment (in Fig. 2c). The effects of the two kinds of networks on species emigration has no significant rule, so the environmental factor such as draught and precipitation maybe play more role (in Fig. 2d).

\subsection{Network structure affects species attributes}
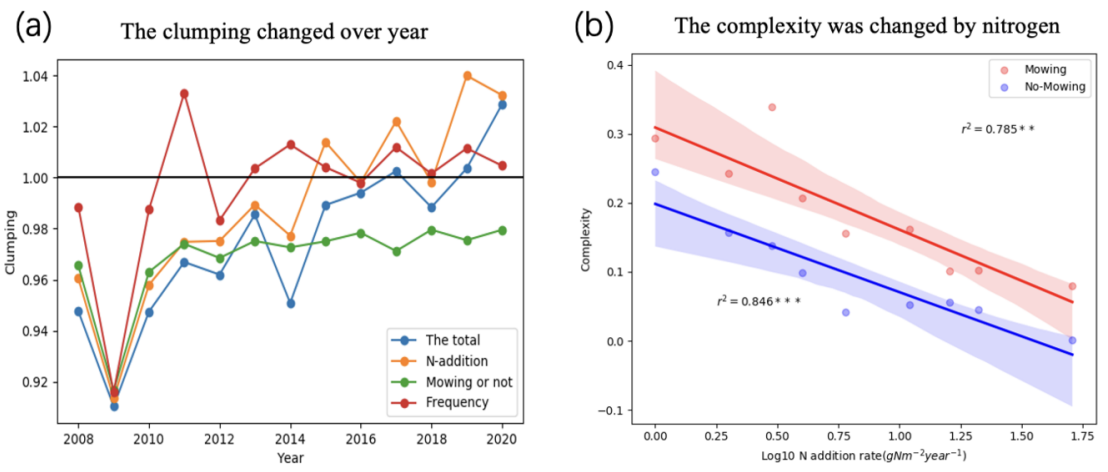

Figure 3 (a) Trends of difference in species-richness distribution for plot group of the total (blue), mowing (green), $\mathrm{N}$-addition (orange), and frequency of $\mathrm{N}$ fertilization (red) are distributed, respectively. The difference between years was measured by Lloyd's ratio from the variance and mean on species richness. Under mowing treatments, the network complexity changed with logarithm of $\mathrm{N}$-addition rate (b). The solid dot in red and blue represent coordinate of network complexity and degeneracy under the same nitrogen $\left(\log _{10}(N)\right)$ with mowing (red) and no-mowing (blue). The solid lines represent linear least square regression lines. With the increase of $\mathrm{N}$ addition rates, complexity decreased significantly, but the results treated with mowing are always above that with no-mowing. Note: ${ }^{* *}<0.01, * * *<0.001$.

As shown in Fig. 3a, with over years, the differences in distribution of species richness gradually increased. Before the experiment, the distribution of species richness in 2008 was relatively uniform, differences of which were small. Water is the most critical resource of the grassland ecosystem,so the drought in 2009 and the beginning $\mathrm{N}$-addition in the year resulted in little difference in the distributions within each group and between the groups (total, mowing, N-addition, frequency, in Fig. 3a). In other words, $\mathrm{N}$ fertilizer intensified the response of the grassland vegetations to the drought, resulting in the most uniform distributions. Nitrogen enrichment was the key factor that caused the difference in species richness distribution, while fertilization frequency and mowing had relatively small effects on it $(R=0.166, \quad P=0.001$, in Fig. S1). With the increase of nitrogen enrichment, the complexity gradually decreased, but the negative effect of nitrogen could be significantly offset by mowing (in Fig. 3b). Nitrogen enrichment led to the expansion of difference in competition levels and the superior species gradually played the dominant role in the networks, resulting in the network degenerated into a structure with more transitive chain (in Fig. S2). 

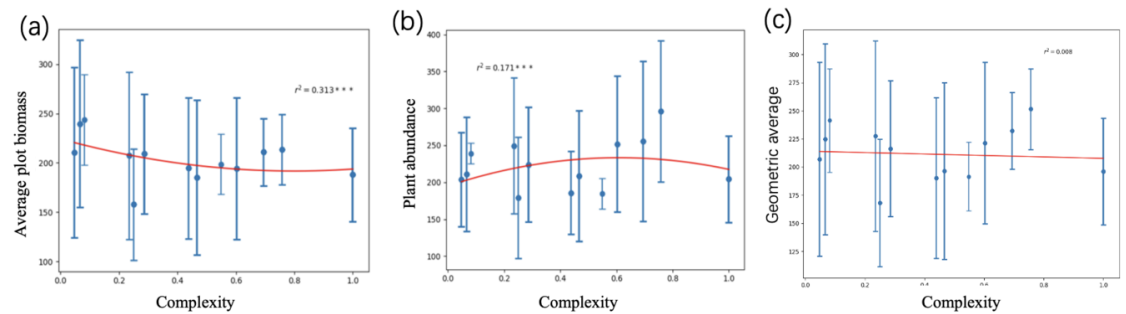

Figure 4 Relationships between average plot biomass (a), plant abundance of plot (b) and network complexity are given, respectively. The least square regression is used to fit the relationships. The blue solid circle represent the mean, the blue line is the error bar, and the red quadratic curve is regression linear. Relationship between geometric average of plot biomass and plant abundance and complexity is also given (c). Note: $* * *$ is $\mathrm{p}<0.001$.

$\mathrm{N}$-addition affected primary productivity of plants, but also network structure. The relationship between biomass and complexity was a significant quadratic curve with down bending direction $\left(r^{2}=0.313, \quad P<\right.$ 0.001 , Fig. 4a). Especially, under high nitrogen fertilization $\left(\mathrm{N}>=2 \mathrm{~g} \mathrm{~N} \cdot \mathrm{m}^{-2} \cdot\right.$ year $\left.^{-1}\right)$ at high frequency (once a month) and without mowing treatment, complexity will have a great negative impact on biomass (in Fig. S3). On the contrary, there was a significant quadratic curve, with an opposite direction, between plant abundance and complexity $\left(r^{2}=0.171, P<0.001\right.$, Fig. 4b). There was a complementary relationship between biomass and plant abundance, which the regression line of geometric average of the two remained almost horizontal. In addition, biomass in short networks was significantly more than that in nested networks $\left(T_{\text {test }}=2.416, P<0.05\right)$. The plants abundance was not able to reflect competitivity of species to resources $\left(T_{\text {test }}=-0.784, P>0.05\right)$. However, biomass and plant abundance both increased in the late stage of the experiment (in Fig. S4).

\subsection{Network structure affects ecological function}

(a)

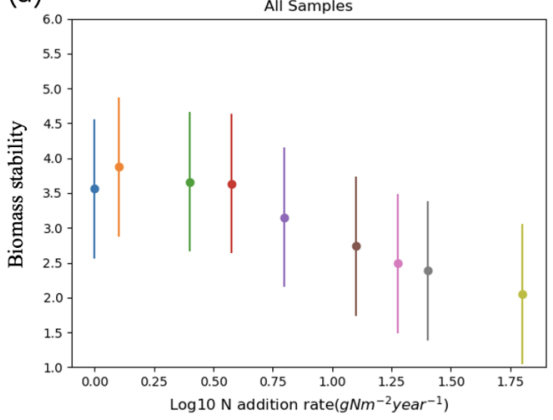

(b)

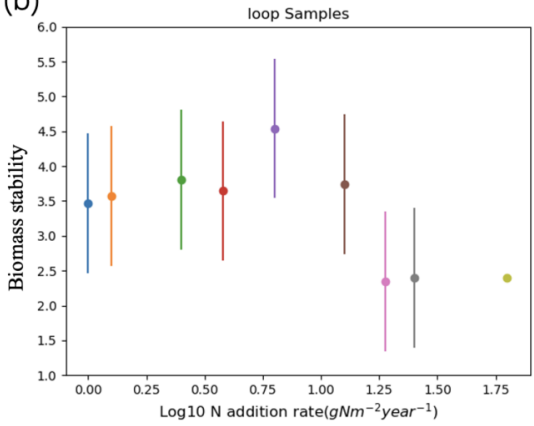

Figure 5 The relationship between stability of plot biomass and logarithm (with base 10) of N-addition rate were given in two samples, all sample plots and (b) loop samples with intransitive structure. The solid circle represented coordinates of plot biomass average $\operatorname{andlog}_{10} N$, and the solid line represented the standard deviation.

With the increase of nitrogen enrichment, the biomass stability decreased and the state of grassland ecosystem became worser and worser comparing with natural state (in Fig. 5a,), because environmental filtering reordered the species dominance. When $\mathrm{N}=1 \mathrm{~g} \mathrm{~N} \cdot \mathrm{m}^{-2} \cdot \mathrm{year}^{-1}$, it was conducive to enhance biomass stability, but $\mathrm{N}$ [?] $2 \mathrm{~g} \mathrm{~N}^{*} \mathrm{~m}^{-2 *}$ year $^{-1}$ is the opposite. 
Fig. 5b given the biomass stability in intransitive competitive structure changes with logarithm of $\mathrm{N}$-addition rates. It was found that the stability performed an increasing trend and then decreasing. Intransitive structure completely offset the negative effect of medium $\mathrm{N}$-addition rates $\left(5,10 \mathrm{~g} \mathrm{~N}^{*} \mathrm{~m}^{-2 *} \mathrm{year}^{-1}\right)$ on the stabilities. But excessive nitrogen enrichments $\left(15,20\right.$, and $50 \mathrm{~g} \mathrm{~N}^{*} \mathrm{~m}^{-2 *}$ year $\left.^{-1}\right)$ completely covered the ecological action of intransitive competition, resulting in the level of the three stabilities similar to that of the all samples.

(a)

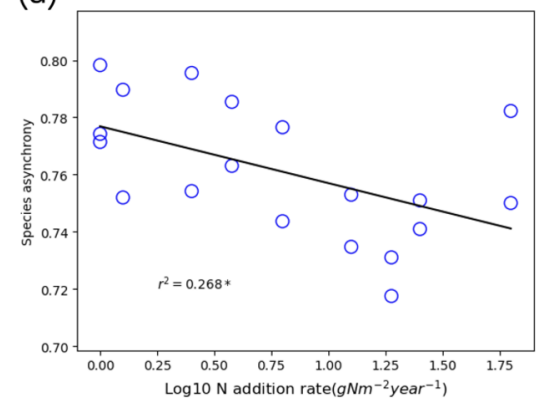

(b)

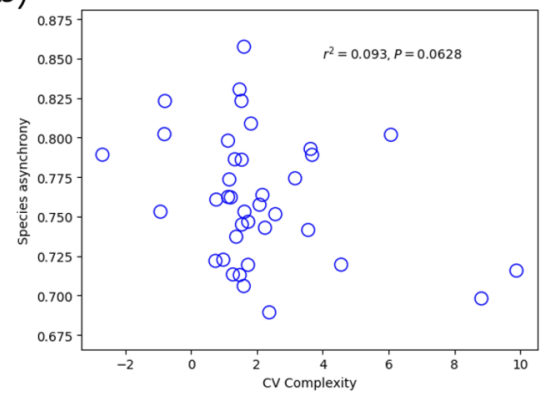

Figure 6 The relationships are given, (a) between species asynchrony and logarithm (with base 10) of N addition rate and (b) between the former and CV complexity (standard variance of network complexity divided by the mean. Solid line isv the linear least square regression. Note: ${ }^{*}<0.05$.

Nitrogen enrichment significantly reduced species asynchrony $\left(r^{2}=0.268, \quad P<0.05\right.$, in Fig. 6a), because it changed species competitive advantage and mobility, weakened complexity and network degeneracy. The increase of $\mathrm{CV}$ complexity had a tendency to reduce species asynchrony, but it was not significant $\left(r^{2}=\right.$ 0.844, $P>0.05$, in Fig. $6 \mathrm{~b})$. So, the external environment was the main factor affecting the species asynchrony rather than network complexity.

\section{Discussion}

\subsection{Effects of network structure on plant community attributes under nitrogen enrichment}

The theoretical and practical approaches on species interactions ignores the more complex chain of indirect interactions that may occur in different natural communities (Gallien 2017a). Gallien (2017b) defined four forms of interspecific interaction in theory and found that intransitive loops can both stabilize and destroy species coexistence, but the length and topological structure of intransitive loop significantly affect intensity and importance of intransitive competition. In reality, species-competition network often is not just a single structure, but multiple simple structures interweaving, controlled the vegetation community. We found that there were the five simple forms of intransitive loop, among which the nested-loop has a widest distribution range in the sample plots, accounting for $76.96 \%$, always along with other forms except for the short loop.

Mathematical studies have shown that intransitive loops with an odd number of species stabilize species coexistence, while loops with an even number of species destabilize species abundance (Vandermeer 2011). Ulrich (2018) found a significant positive correlation between the nesting degree of network structure and the Alpha diversity in European salt marsh plant communities. Our results showed that, in terms of long-term effects on maintaining species diversity, nested network was always in an absolute advantage at the small (Alpha) and large-scale (Gamma) diversity, but had a certain delay effect on the Beta diversity, indicating that the effect of the ecosystem needed time to offset the negative effect of nitrogen deposition. In addition, nested network was also conducive to introduction of new species, suggesting that more complex competition can provide more chance to new species. There was no significant difference in species emigration between the two networks, while there may be yet other factors affecting on the difference. 
Intransitive competition is likely to be the main reason for the construction of plant community. High intensity habitat disturbance results in less structured competition as well as less intransitive competition loops in plant communities (Ulrich et al. 2018). Our results showed that environmental filtering affects not only the attributes of the steppe communities, but also the competitive structure within the communities. With the increase of nitrogen enrichment, the complexity and degeneracy of network decreased simultaneously, indicating that high $\mathrm{N}$-addition rates will destroy the soil environment on which vegetation depends for survival and then interfere with the interspecific interactions, which simplify the network structure and gradually clarify the competition levels, or expand the difference in the levels (Sun et al. 2021). Expansion of differences in the levels also lead to an easy natural selection among species, which generally existed in communities. The difference between the two kinds of networks was mainly characterized by colonization and emigration. The plots with nested networks had more resource utilization and stronger colonization potential for new species, resulting in the transition from the competition effect to the promotion effect.

The productivity of the plots treated with mowing was higher than that with no mowing (in Fig. S3be), so mowing management can partially offset the negative effects of nitrogen enrichment. This is mainly because mowing will increase soil nutrient loss and cause nutrient imbalance (Giese et al. 2013; Liu et al. 2015), thus intensify the competition for nutrients by lessening the competitivity of the dominant species. Mowing can also increase soil surface temperature by increasing ground irradiance (Wan et al. 2002), thereby increase the synchronicity of species responses to climatic conditions during growing season (Shestakova et al. 2016). In the temperate steppe, nutrients and light are important resources for plant growth, and mowing leads to redistribution of available nutrients and light, this may increase interspecific competition (Zhang et al. 2017). So, mowing can remove part of nitrogen enrichment, relieve the environmental pressure and promote plant growth. On the other hand, mowing disrupts the competitive balance of species networks, weakens the competitiveness of dominant species, resulting in reducing the differences in the levels of competition, promoting balanced growth of species, and maintaining the level of species diversity.

\subsection{Effect of network complexity on plant community function under nitrogen enrichment}

Empirical studies have shown that Intransitive competition, which usually occurs in communities along with direct interactions, has important effects on community structure and functions (Maynard et al. 2017a; Soliveres et al. 2015). Niche differences among species responds asynchronously to environmental fluctuations, resulting in asynchronous population dynamics and ultimately more stable overall ecosystem attributes (Loreau and De Mazancourt 2013). Species asynchrony can stabilize communities by compensating for growth in species or functional groups (Song and Yu 2015). Thus, species asynchrony is the main mechanism regulating the temporal stability of the community (Zhou et al. 2020; Taofeek et al. 2021).

The directly positive effect of nitrogen enrichment on species asynchronism is due to dynamic compensation, which increases interspecific competition for light resources (Schluter 1984; Micheli et al. 1999; Grman et al. 2010) and ultimately result in higher species asynchrony. The indirect effect of nitrogen addition on species asynchronism is due to the fact that nitrogen enrichment induces a decrease in species diversity, thus weakening the stabilizing effect of species asynchronism on the community (Yachi and Loreau,1999; Yang et al. 2012). High level of nitrogen enrichment may reduce intensity of competition for nutrient resources, thus reducing the asynchronous degree of species fluctuations (Song and Yu 2015). In high nitrogen enrichment environment, competitive order of dominant species changes and some rare species even disappear completely (Zhou et al. 2020). Our results showed that species asynchrony was synchronized with grassland ecosystem response to N-addition rates, which was consistent with previous findings (Liu et al. 2019). The effect of CV complexity on species asynchrony was not significant, thus the external environmental disturbance was the main factor affecting the species asynchrony rather than network complexity. Although the fierce interspecific competition easily leads to species replacement, a loop-structured network basically maintains the balance of species asynchrony. Thus, species asynchronous compensation has less effect on the stability in plot with loop structure.

In the sample plot of intransitive competition network, the damage of high nitrogen enrichment ([?]15 $\mathrm{g}$ 
$\mathrm{N} \cdot \mathrm{m}^{-2} \cdot$ year $^{-1}$ ) to the temporal stability of the ecosystem was basically the same as that of all samples. This indicated that under the high nitrogen enrichment, the absorption of nitrogen by plants reaches saturation and the positive effect on the ecosystem stability disappears (Zhou et al. 2020). Excessive nitrogen enrichment also accelerates vegetation transpiration, which leads to the decrease of water resources and thus aggravates the community instability (Chen et al. 2016). Under medium nitrogen enrichments $\left(5,10 \mathrm{~g} \mathrm{~N} \cdot \mathrm{m}^{-2} \cdot \mathrm{year}^{-1}\right)$, the temporal stability of the plots with loop structure had a significant increase, which inferred that the intransitive competition under the nitrogen enrichments is conducive to enhance the ecosystem stability and counteracts the negative effect of nitrogen enrichment apparently. Intransitive competition increased local diversity and small-scale species replacement, which may be the reason why network complexity did not have significant negative effect on species asynchronism. Therefore, in addition to the compensative effect of species asynchronism on ecosystem stability, we believe that the structural attributes of species-competition network may be another important internal mechanism to maintain the stability of the grassland ecosystem.

Community attributes have an obvious complementary relation in term of complexity. The relationship between network complexity and plot biomass was a significantly quadratic curve with down bending direction, while that between plant abundance and complexity was also a quadratic curve but with opposite direction. This shows that when plot biomass is low, it will be compensated by high plant abundance, and vice versa. The bending direction of the two curves also indicated that the competition structure may be a mechanism for self-recovery of grassland ecosystem, which can alleviate the high intensity of external interference.

\section{Conclusion}

In this paper, the response of plant communities to intransitive competition structure under nitrogen enrichment was investigated from the perspective of interspecific competition. We found that the overall structure of a real species-competition network was always very complex, weaving up of a variety of simple structures. Compared with short network, nested network introduced new species with higher colonization rate and had a long-term temporal mechanism to maintain the small-scale Alpha diversity, but had a significant lag effect on regulating the large-scale Gamma diversity. With change of network complexity, the biomass and the plant abundance showed quadratic curves with opposite bending direction, demonstrating a complementary relationship. The response of species asynchrony and grassland ecosystem stability decreased with the increase of nitrogen enrichment synchronously. Fortunately, at low and medium nitrogen enrichment, intransitive competitive network offset the negative effect of nitrogen. Intransitive competition structure is likely to be the internal mechanism to resist the external environmental disturbace and maintain the grassland ecosystem stability. In the future, we will focus on the changes in the intensity of species competition within network and analyze the ecological information behind them. We hope that the results of this study can enrich the theory of nitrogen deposition affecting interspecific interactions among species and provide theoretical support for coping with the effects of nitrogen deposition.

\section{References}

Allesina, S., \& Levine, J. M. (2011). A competitive network theory of species diversity. Proceedings of the National Academy of Sciences of the United States of America, 108, 5638-5642. Doi: 10.1073/pnas.1014428108.

Aschehoug, E. T., Brooker, R., Atwater, D. Z., Maron, J. L., \& Callaway, R. M. (2016). The mechanisms and consequences of interspecific competition in plants. Annual Review of Ecology, Evolution and Systematics, 47, 263-281. Doi:10.1146/annurev ecolsys-121415-032123.

Chen, W., Zhang, Y., Mai, X., \& Shen, Y. (2016). Multiple mechanisms contributed to the reduced stability of Inner Mongolia grassland ecosystem following nitrogen enrichment. Plant Soil, 409, 283-296. Doi:10.1007/s11104-016-2967-1.

Clark, C. M., \& Tilman, D. (2008). Loss of plant species after chronic low-level nitrogen deposition to prairie grasslands. Nature, 451,712-715. Doi:10.1038/nature06503. 
Douda, J., Doudova, J., Hulik, J., Havrdova, A. \& Boublik, K. (2018). Reduced competition enhances community temporal stability under conditions of increasing environmental stress. Ecology, 10, 2207-2216. Doi:10.1002/ecy.2466.

Dufour, A., Dagallah, F., Wagnr, H. H., Guisan, A., \& Buttler, A. (2006). Plant species richness and environmental heterogeneity in a mountain landscape: Effects of variability and spatial configuration. Ecography, 29, 573-584. Doi:10.1111/j.0906-7590.2006.04605.x.

Engel, E. C., \& Wetzin, J. F. (2008). Can community composition be predicted from pairwise species interactions? Plant Ecology, 195, 77-85. Doi:10.1007/s11258-007-9300-2.

Fraterrigo, J. M., Turner, M. G., Pearson, S. M. \& Dixon, P. (2005). Effects of past land use on spatial heterogeneity of soil nutrients in southern Appalachian forests. Ecological Monographs, 75, 215-230. Doi:10.1890/03-0475.

Freckleton, R. P., \& Watkinson, A. R. (2001). Predicting competition coefficients for plant mixtures: reciprocity, transitivity and correlations with life-history traits. Ecology Letters, 4, 348-357. Doi:10.1046/j.14610248.2001.00231.x

Gallien, L. (2017a). Intransitive competition and its effects on community functional diversity. Oikos, 126, 615-623. Doi:10.1111/oik.04033.

Gallien, L., Zimmermann, N. E., Levine, J. M. \& Adler, P. B. (2017b). The effects of intransitive competition on coexistence. Ecology Letters. e12775. Doi:10.1111/ele.12775.

Giese, M., Brueck, H., Gao, Y. Z., Lin, S., Steffens, M., Kögel-Knabner, I., Glindemann, T., Susenbeth, A., Taube, F., Butterbach-Bahl, K., Zheng, X. H., Hoffmann, C., Bai, Y. F., \& Han, X. G. (2013). N balance and cycling of Inner Mongolia typical steppe: a comprehensive case study of grazing effects. Ecological Monographs, 83, 195-219. Doi:10.1890/12-0114.1.

Grman, E., Lau, J.A., Schoolmaster, D.R. \& Gross, K. L. (2010). Mechanisms contributing to stability in ecosystem function depend on the environmental context. Ecology Letters, 13,1400-1410. Doi:10.1111/j.14610248.2010.01533.x.

Gross, N., Bagousse-Pinguet Y. L., Liancourt, P., Berdugo, M., Gotelli, N. J., \& Maestre, F. T. (2017). Functional trait diversity maximizes ecosystem multifunctionality. Nature Ecology \& Evolution, 1(5), 0132. Doi:10.1038/s41559-017-0132.

Laird, R. A., \& Schamp, B. S. (2006). Competitive intransitivity promotes species co-existence. The American Naturalist, 168, 182-193. Doi:10.1086/506259.

Liu, J., Li, X., Ma, Q., Zhang, X., Chen, Y., Isbell, F., \& Wang, D. (2019). Nitrogen addition reduced ecosystem stability regardless of its impacts on plant diversity. Journal of Ecology, 107, 2427-2435. Doi:10.1111/1365- -2745.13187.

Liu, N., Kan, H. M., Yang, G. W., \& Zhang, Y. J. (2015). Changes in plant, soil, and microbes in a typical steppe from simulated grazing: explaining potential change in soil C. Ecological Monographs, 85, 269-286. Doi: $10.1890 / 14-1368.1$.

Lloyd, M. (1967). 'Mean crowding'. Journal of Animal Ecology, 36, 1-30.

Loreau, M., \& de Mazancourt, C. (2008). Species synchrony and its drivers: neutral and nonneutral community dynamics in fluctuating environments. The American Naturalist, 172, E48-E66. Doi:10.1086/589746.

Loreau, M., \& de Mazancourt, C. (2013). Biodiversity and ecosystem stability: a synthesis of underlying mechanisms. Ecology Letters, 16, 106-115. Doi:10.1111/ele.12073.

Luo, J., \& Magee, C. L. (2011). Detecting evolving patterns of self-organizing networks by flow hierarchy measurement. Complexity, 16, 53-61. Doi: 10.1002/cplx.20368. 
Ma, Z. Y., Liu, H. Y., Mi, Z. R., Zhang, Z. H., Wang, Y. G., Xu, W., Jiang, L., \& He, J. S. (2017). Climate warming reduces the temporal stability of plant community biomass production. Nature Communications, 8, 15378. Doi:10.1038/NCOMMS15378.

Maynard, D. S., Leonard, K. E., Drake, J. M., Hall, D. W., Crowther, T. W., \& Bradford, M. A. (2015). Modelling the multidimensional niche by linking functional traits to competitive performance. Proceedings of the Royal Society of London B, 282, e20150516. Doi:10.1098/rspb.2015.0516.

Maynard, D. S., Bradford, M. A., Lindner, D. L., van Diepen, L. T. A., Frey, S. D., Glaeser, J. A., \& Crowther, T. W. (2017a). Diversity begets diversity in competition for space. Nature Ecology and Evolution, 1, 0156. Doi:10.1038/s41559-017-0156.

Maynard, D. S., Crowther, T. W., \& Bradford, M. A. (2017b). The competitive network determines the direction of the diversity-function relationship. Proceedings of the National Academy of Sciences of the United States of America, 114, 11464-11469. Doi:10.1073/pnas.1712211114.

Micheli, F., Cottingham, K. L., Bascompte, J., Bjornstad, O. N., Eckert, G. L., Fischer, J. M., Keitt, T. H., Kendall, B. E., Klug, J. L., \& Rusak, J. A. (1999). The dual nature of community variability. Oikos, 85, 161-169. Doi:10.2307/3546802.

Mouillot, D., Villéger, S., Scherer-Lorenzen, M., \& Mason, N. W. H. (2011). Functional Structure of biological communities predicts ecosystem multifunctionality. PLOS ONE, 6, e17476. Doi: 10.1371/journal.pone.0017476.

Rosenzweig, M. L. (1971). Paradox of enrichment: destabilization of exploitation ecosystems in ecological time. Science, 171, 385-387. Doi:10.2307/1731139.

Schluter, D. (1984). A variance test for detecting species associations, with some example applications. Ecology, 65, 998-1005. Doi:10.2307/1938071.

Shestakova, T. A., Gutiérrez, E., Kirdyanov, A. V., Camarero, J. J., Génova, M., Knorre, A. A., Linares, J. C., Resco de D, V., Sánchez-Salguero, R., \& Voltas, J. (2016). Forests synchronize their growth in contrasting Eurasian regions in response to climate warming. Proceedings of the National Academy of Sciences of the United States of America, 113, 662-667. Doi:10.1073/pnas.1514717113.

Socher, S. A., Prati, D., Boch, S., Mueller, J., Baumbach, H., Gockel, S., Hemp, A., Schoening, I., Wells, K., Buscot, F., Kalko, E. K. V., Linsenmair, K. E., Schulze, E.-D., Weisser, W. W., \& Fischer, M. (2013). Interacting effects of fertilization, mowing and grazing on plant species diversity of 1500 grasslands in Germany differ between regions. Basic and Applied Ecology, 14, 126-136. Doi:10.1016/j.baae.2012.12.003.

Soliveres, S., Maestre, F. T., Ulrich, W., Manning, P., Boch, S., Bowker, M., \& Allan, E. (2015). Intransitive competition is widespread in plant communities and maintains species richness. Ecology Letters, 18, 790-798. Doi:10.1111/ele.12456.

Song, M., \& Yu, F. (2015). Reduced compensatory effects explain the nitrogen-mediated reduction in stability of an alpine meadow on the Tibetan Plateau. New Phytol, 207,70-77. Doi:10.1111/nph.13329.

Sun Q. Q., Yang J. J., Wang, S., Yang, F. Y., Zhang, G. M., Wei, C. Z., Han X. G. \& Li, J. S. (2021). Nitrogen enrichment affects the competition network of aboveground species on the Inner Mongolia steppe. Global Ecology and Conservation, 31, e01826.Doi:10.1016/j.gecco.2021.e01826.

Tilman, D. (1987). Secondary succession and the pattern of plant dominance along experimental nitrogen gradients. Ecological Monographs, 57,189-214.

Tilman, D. (1999). The ecological consequences of changes in biodiversity: a search for general principles. Ecology, 80, 1455-1474.

Taofeek O. M., Xu, C., Yu, Q., Yang, Y., Jing, M. G., Jia, X. T., Jaman, M. S., Dam, Q., Knapp, A. K., Collins, S. L., Luo, Y. Q., Luo, W. T., Zuo, X. A., Xin, X. P., Han, X. G., \& Smith, M. D. (2021). Species 
asynchrony stabilizes productivity under extreme drought across Northern China grasslands. Journal of Ecology, 109(4), 1665-1675. Doi:10.1111/1365-2745.13587.

Ulrich, W., Soliveres, S., Kryszewski, W., Maestre, F. T., \& Gotelli, N. J. (2014). Matrix models for quantifying competitive intransitivity from species abundance data. Oikos, 123, 1057-1070. Doi:10.1111/oik.01217.

Ulrich, W., Jabot, F., \& Gotelli, N. J. (2017). Competitive interactions change the pattern of species cooccurrences under neutral dispersal. Oikos, 126, 91-100. Doi:10.1111/oik.03392.

Ulrich, W., Kubota, Y., Piernik, A., \& Gotelli, N. J. (2018). Functional attributes and environmental characteristics drive the degree of competitive intransitivity in European saltmarsh plant communities. Journal of Ecology, 106, 865-876. Doi:10.1111/1365-2745.12958.

Vandermeer, J. (2011). Intransitive loops in ecosystem models: from stable foci to heteroclinic cycles. Ecological. Ecological Complexity, 8, 92-97. Doi:10.1016/j.ecocom.2010.08.00.

Wan, S., Luo, Y., \& Wallace, L. L. (2002). Changes in microclimate induced by experimental warming and clipping in tallgrass prairie. Global Change Biology, 8,754-768. Doi:10.1046/j.1365-2486.2002.00510.x.

Wang, S. P. \& Loreau, M. (2014). Ecosystem stability in space: a, b and c variability. Ecology Letters, 17, 891-901. Doi:10.1111/ele.12292.

Wang, S., Zhang, G. M. \& Li, J. S. (2020). Effects of simulated nitrogen deposition on the species networks of inner Mongolia grassland. Global Ecology and Conservation. 24, e01398. Doi: 10.1016/j.gecco.2020.e01398.

Wesche, K., Krause, B., Culmsee, H. \& Leuschner, C. (2012). Fifty years of change in Central European grassland vegetation: large losses in species richness and animal-pollinated plants. Biological Conservation, 150, 76-85. Doi: 10.1016/j.biocon.2012.02.015.

Western, D. (2001). Human-modified ecosystems and future evolution. Proceedings of the national academy of sciences, 98, 5458-5465. Doi: 10.1073/pnas.101093598.

Wilcox, K.R., Tredennick, A.T., Koerner, S.E., Grman, E., Hallett, L.M., Avolio, M.L. et al. La P., Kimberly J., Houseman, G. R., Isbell, F., Johnson, D. S., Alatalo, J. M., Baldwin, A. H., Bork, E. W., Boughton, E. H., Bowman, W. D., Britton, A. J., Cahill, J. F., Collins, S. L., Du, G. Z., Eskelinen, A., Gough, L., Jentsch, A., Kern, C., Klanderud, K., Knapp, A. K., Kreyling, J., Luo, Y. Q., McLaren, J. R., Megonigal, P., Onipchenko,V., Prevéy, J., Price, J. N., Robinson, C. H., Sala, O. E., Smith, M. D., Soudzilovskaia, N. A. „Souza, L., Tilman, D., White, S. R., Xu, Z. W., Yahdjian, L., Yu, Q., Zhang, P. F., Zhang, Y. H., \& Gurevitch, J. (2017). Asynchrony among local communities stabilises ecosystem function of metacommunities. Ecology Letters, 20, 1534-1545. Doi:10.1111/ele.12861

Yachi, S., \& Loreau, M. (1999). Biodiversity and ecosystem productivity in a fluctuating environment: the insurance hypothesis. PNAS, 96, 1463-1468. Doi:10.1073/pnas.96.4.1463.

Yang, H., Jiang, L., Li, L., Li, A., Wu, M., \& Wan, S. (2012). Diversity-dependent stability under mowing and nutrient addition: evidence from a 7-year grassland experiment. Ecology Letters, 15, 619-626. Doi:10.1111/j.1461-0248.2012.01778.x.

Zhang, Y. H., Feng, J. C., Isbell, F., Lü, X. T., \& Han, X. G. (2015). Productivity depends more on the rate than the frequency of $\mathrm{N}$ addition in a temperate grassland. Scientific Reports, 5,12558. Doi: $10.1038 /$ srep 12558 .

Zhang, Y. H., Loreau, M., He, N. P., Zhang, G. M., Han, X. G. (2017). Mowing exacerbates the loss of ecosystem stability under nitrogen enrichment in a temperate grassland. Functional Ecology, 31, 1637-1646. Doi: $10.1111 / 1365-2435.12850$.

Zhang, Y. H., Feng, J. C., He, N.P., Loreau, M., Han, X. G., \& Lin, J. (2019). Nitrogen addition does not reduce the role of spatial asynchrony in stabilizing grassland communities. Ecology Letters, e13212. Doi:10.1111/ele.13212. 
Zhou, M., Yang, Q., Zhang. H.J., Yao, X.D., Zeng, W.J., \& Wang, W. (2020). Plant community temporal stability in response to nitrogen addition among different degraded grasslands. Science of The Total Environment, 729, 138886. Doi:10.1016/j.scitotenv.2020.138886. 